\title{
Carcinomatous Ascites
}

National Cancer Institute

\section{Source}

National Cancer Institute. Carcinomatous Ascites. NCI Thesaurus. Code C35654.

Accumulation of fluid in the peritoneal cavity resulting from the growth of primary or metastatic carcinoma in the peritoneum. 